http://dx.doi.org/10.5007/2175-7984.2012v11n20p23

\title{
A SOCIOLOGIA WEBERIANA DA CIÊNCIA
}

Carlos Eduardo Sell ${ }^{1}$

\section{Resumo}

O artigo busca levantar subsídios para a reconstrução da análise weberiana da ciência enquanto fenômeno cultural e social. A intenção é demonstrar que a abordagem weberiana sobre o saber científico possui uma dimensão ao mesmo tempo geral (como processo histórico-cultural) e particular (como esfera social). Com base no paradigma da racionalização, procurase evidenciar que a ciência ocupa um papel essencial na análise que Max Weber realiza do processo cultural de racionalização teórica (desencantamento do mundo) e no processo social de racionalização formal das instituições modernas. Ao final, destaca-se ainda a dimensão crítico-normativa que a tematização weberiana da ciência adquire em sua avaliação dos paradoxos e dos desafios éticos e políticos da era moderna.

Palavras-chave: Weber, ciência, racionalidade, racionalismo.

$\mathrm{N}$ a brilhante sistematização que Jürgen Habermas (1987, p. 214 226) nos oferece da Observação Preliminar (Vorbemerkung) ${ }^{2}$ dos

1 Doutor em Sociologia Política (UFSC) e Professor do Programa de Pós-Graduação em Sociologia Política da Universidade Federal de Santa Catarina. Desenvolve projeto de pesquisa (Produtividade Científica - $\mathrm{CNPq}$ ) sobre a racionalidade e racionalismo na sociologia da religião de Max Weber. Contato: sell@cfh.ufsc.br.

2 Nunca é demais chamar a atenção para o fato de que a "Author's Introduction" (como é chamada nas edições em inglês) abre e situa os amplos Ensaios Reunidos de Sociologia da Religião (Gesammelte Aufsätze zur Religionssoziologie) de Max Weber e, por isso, foi colocada por ele antes do primeiro dos textos que compõem aquela coleção: A ética protestante e $o$ 'espírito' do capitalismo. Isto não pode levar o leitor a considerar que se trate de uma introdução específica para esta obra, como nos induz a pensar a tradução feita, ainda em 1930, por Talcott Parsons, e que foi reproduzida na sua subsequente tradução para o português (WEBER, 1996, p. 01-18). Ambos os textos foram escritos em períodos diferentes. 
Ensaios Reunidos de Sociologia da Religião, texto no qual Max Weber nos aponta o escopo de seus estudos histórico-comparativos, podemos perceber que o saber científico foi considerado por ele como um dos fenômenos essenciais da modernidade. De fato, consultando textualmente o escrito em questão, a ciência é nomeada logo como o primeiro dos exemplos das formas racionalizadas da vida moderna: "apenas no Ocidente existe a 'ciência' num estágio de desenvolvimento que atualmente reconhecemos como "válido" (WEBER; GARS I, 1988, p. 01). Weber não deixa de notar que podemos encontrar conhecimentos empíricos e observações de grande acuidade em outras civilizações, como na astronomia babilônica, na geometria, ciência natural, teoria política e no direito racional indianos, bem como na historiografia chinesa. Mas em todos estes casos faltam os elementos específicos (o conceito e o método experimental) que dão unidade e consistência aos procedimentos racionais e sistemáticos que caracterizam a moderna ciência ocidental.

É bem verdade que, ainda seguindo a exposição sistemática de Habermas, os fenômenos do racionalismo ocidental nos quais Weber irá concentrar sua maior atenção são a economia capitalista e o Estado Burocrático, restando aos outros temas o lugar de preocupações subsidiárias. Mas, se a esfera econômica e política são sua preocupação primordial, isto não significa que o sejam de forma exclusiva e nem excludente, pois retomando a lista dos fenômenos elencados pelo próprio Weber neste mesmo prólogo, surpreendem as múltiplas manifestações do racionalismo não apenas nos sistemas sociais de ação (Estado e Mercado), mas também no sistema da personalidade (modo metódico de vida), bem como nas esferas culturais em sua dimensão expressiva (arte autônoma), normativa (moral e direito) e cognitiva (ciência moderna e técnica). Na perspectiva weberiana, a racionalização das esferas sociais de vida não era um fenômeno que atravessava apenas o âmbito econômico e político recobrindo, virtualmente, todas as dimensões da vida em tempos modernos.

Diante desta multiplicidade de fenômenos, qual o peso que o tema da ciência possui na reflexão weberiana? Em que medida 
pode-se localizar, neste autor, os primórdios de uma "sociologia da ciência"? De que forma sua análise da ciência insere-se em sua teoria geral do processo de racionalização crescente? Sem perder de vista o fato de que a ciência não ocupa na pesquisa weberiana o mesmo espaço quantitativo mobilizado em suas amplas reflexões sobre a religião, o mercado ou a dominação política, entre outros temas, gostaria de demonstrar que, malgré tout, sua reflexão a respeito deste assunto pode ser situada, em termos qualitativos, no coração de suas preocupações analíticas. $\mathrm{O}$ argumento consiste em mostrar que se partimos da perspectiva da racionalização, a ciência não representa apenas um apêndice em sua teoria. Bem ao contrário, o tema do saber científico situa-se na zona de confluência de sua ampla sociologia histórico-comparada das civilizações mundiais e de sua reflexão sobre a sociedade moderna. Ao efetuar este movimento busco não apenas situar a interpretação weberiana da ciência no quadro maior de sua sociologia global (sem a qual, assim penso, ela não ganha inteligibilidade), mas também aponto para os elementos que nos remetem para uma (proto) sociologia weberiana da ciência, como campo específico de estudo ${ }^{3}$, cujos germens, assim o creio, também se pode encontrar em suas obras ${ }^{4}$.

\section{Racionalismo ocidental}

A busca por identificar uma sociologia weberiana da ciência à luz de sua abordagem sócio-histórica dos processos de racionalização não constitui apenas uma escolha metodológica aleatória.

3 Área de trabalho científico da qual Weber não foi, certamente, o fundador, mas na qual exerceu influência direta e determinante. A começar pelos não menos célebres iniciadores da sociologia do conhecimento (Karl Mannheim) e da própria sociologia da ciência (Robert Merton, 1970 [1938]). Para a discussão da influência de Weber na tese de Merton ver também Cohen (1990).

4 Nesta direção, procuro dar continuidade aos esforços pioneiros contidos nos trabalhos de Fernandes (2000), Trigueiro (2000) e Menezes (2000). No âmbito da bibliografia internacional, consulte-se: Tenbruck (1974), Lassman e Velody (1989), Schroeder (1995), Oakes (2001), Schroeder e Swedberg (2002) e Maley (2004). 


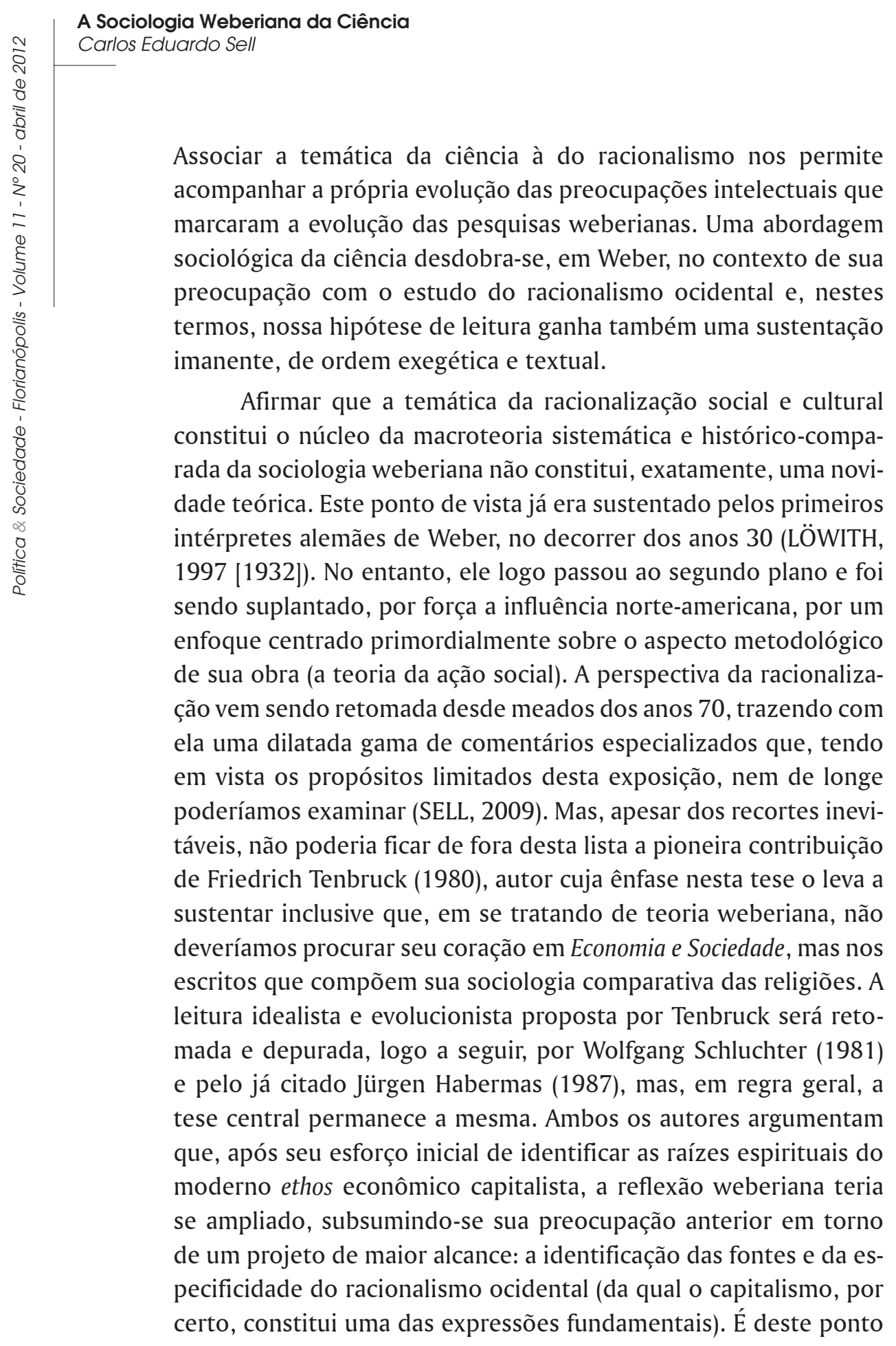


de vista que devemos ler, por exemplo, a afirmação de Weber na já citada Observação Preliminar aos seus estudos histórico-civilizacionais, e que constitui uma verdadeira súmula de seu projeto intelectual: "Por isso, surge novamente o problema de reconhecer a peculiaridade específica do racionalismo ocidental, e, dentre deste moderno racionalismo ocidental, o de esclarecer a sua origem" (WEBER; GARS I, 1988, p. 12).

Esta ótica de interpretação sustenta que a ampliação das preocupações analíticas de Weber pode ser documentada depois de 1910, exatamente no período em que ele começa a empenhar-se nos dois projetos editoriais que irão mobilizar seus últimos anos de vida: a redação do escrito postumamente intitulado Economia e Sociedade e os estudos que compõem A ética econômica das religiões mundiais. Neste caso, estaríamos diante de projetos complementares que, lidos sob a perspectiva da racionalização, apontam para a dupla preocupação de Weber: identificar as raízes e a especificidade da vida social moderna, ou seja, proceder à identificação genético-histórica e a caracterização sistemático-sociológica das formas sociais racionalizadas do Ocidente. Obviamente, esta proposta de leitura e interpretação não é unânime nem homogênea, mas vou assumi-la aqui com o duplo propósito de demonstrar (ainda nesta seção) como uma abordagem sociológica da ciência surge associada aos escritos em que Weber dedica-se ao tema do racionalismo; e por outro lado, para sustentar (nas seções seguintes) que o tema da sociologia weberiana da ciência precisa ser compreendido (em termos analíticos) no quadro global de sua sociologia da religião (leia-se, da modernidade).

Para tornar esta proposta consistente temos de mostrar, pelo menos, que a tematização sociológica da ciência também ganha relevo nos textos weberianos a partir de 1910. A dificuldade óbvia desta leitura parece residir no fato de que ela não considera a intensa polêmica de Weber em torno do estatuto epistemológico das "ciências do espírito" (Methodenstreit), cujo ponto alto é o seu famoso ensaio sobre "A 'objetividade' do conhecimento na ciência social e na ciência política” (WEBER, 1992), escrito ainda em 1904 
(anterior, portanto, ao período acima considerado). Sem menosprezar o fato não menos certo de que a ampla gama de textos que Weber escreveu sobre este tema envolve, necessariamente, uma "doutrina da ciência" (Wissenchaftslehre), a questão é que esta se desenvolve no registro da epistemologia (filosofia), tendo como foco o caso das ciências humanas (SAINT-PIERRE, 1994; COHN, 2003; RINGER, 2004). Em outra direção, isto implica afirmar que, salvo de forma indireta, em sua discussão epistemológica não está em jogo à ciência enquanto fenômeno social, sua evolução histórica ou mesmo seu papel no quadro da vida moderna. Nela encontramos muito pouco de uma "sociologia da ciência" (em um sentido mais estrito e rigoroso), objeto que nos interessa aqui. Razão pela qual, bem pesados os riscos deste recorte, e sem menosprezar a mais do que evidente importância destes textos, abrirei mão da sua análise ${ }^{5}$.

A ciência, como fenômeno social especificamente moderno, é uma preocupação que ganha relevo e acento apenas no Weber "tardio". Se o primeiro insight de Weber em torno da amplitude do racionalismo na esfera ocidental pode ser localizado em sua percepção da música (WAIZBORT, 1995, p. 24), a ciência ocupa o posto contrário: é um dos últimos (mas não menos importantes) temas que Weber vai destacar. Testemunha clara nesta edição é o fato de que a atividade científica, enquanto objeto sociológico, não possui um capítulo sistemático nas partes mais antigas de Economia e Sociedade, como é o caso da economia, do direito, da dominação, da religião, da estratificação social e até da nação. Aliás, quem examinar a versão em português de Economia e Sociedade verá, por exemplo, que no capítulo $\mathrm{V}$ (sociologia da religião), ao tratar da relação entre ética religiosa e mundo, Weber (1994, p. 385-404) discute as esferas da economia, política, erótica e estética, mas ainda não se refere à esfera científica. Porém, sabemos, pelas investigações exegéticas disponíveis (SCHLUCHTER, 1979, p. 59-64),

5 Razão que não impede, de qualquer forma, a utilização destas fontes com os mesmos propósitos (veja-se, por exemplo, Mattedi, 2006, p. 52-62). 
que esta parte antiga de Economia e Sociedade será retomada e ampliada mais tarde para compor um texto independente intitulado Consideração Intermediária [Zwischenbetrachtung], denominação anódina que não nos deve confundir quanto à sua importância teórica primordial na sociologia da religião de Weber ${ }^{6}$. Neste novo escrito, publicado pela primeira vez em 1915, uma nova dimensão é anexada ao quadro antes existente, com o claro intuito de pensar as relações entre a esfera religiosa e esta outra e fundamental esfera social autônoma do mundo moderno: a esfera intelectual (ciência).

Quais seriam os motivos pelos quais o tema da ciência, enquanto fenômeno social, desdobre-se apenas tão tardiamente na obra de Weber? Não sei se esta pergunta já foi feita. Mas, se a questão for relevante e, se respostas existem, talvez elas possam ser encontradas nas linhas e entrelinhas deste que, sem sombra de dúvida, constitui o centro da sociologia (sociologia, bem dito, e não apenas epistemologia) weberiana da ciência: a célebre conferência $A$ ciência como vocação. Apesar das muitas dúvidas (e confusões) a respeito das datas em que esta conferência foi realmente proferida, a exegese atual (SCHLUCHTER, 2000, p. 104-109) julga poder apontar o dia com precisão: 7 de novembro de 1917, ou seja, dois anos antes da conferência $A$ política como vocação, esta outra proferida no dia 28 de janeiro de 1919.

O escrito A ciência como vocação e o tópico da Consideração Intermediária que trata da esfera intelectual constituem as fontes textuais a partir do qual procuro reconstruir a sociologia weberiana da ciência. As indicações dos principais intérpretes de Weber apontam para o fato de que a datação destes escritos pertence ao final do período de produção de Weber, exatamente na fase em que sua ampla visão reconstrutiva da história à luz dos múltiplos e diferenciados processos de racionalização ia ganhando sua forma definitiva. Este dado confirma nossa premissa de que o tema da

6 Em português, o texto encontra-se disponível na coletânea de Gerth e Mills, denominada apenas com aquele que era o subtítulo do texto original: "Rejeições religiosas do mundo e suas direções" (WEBER, 1982, p. 371-412). 


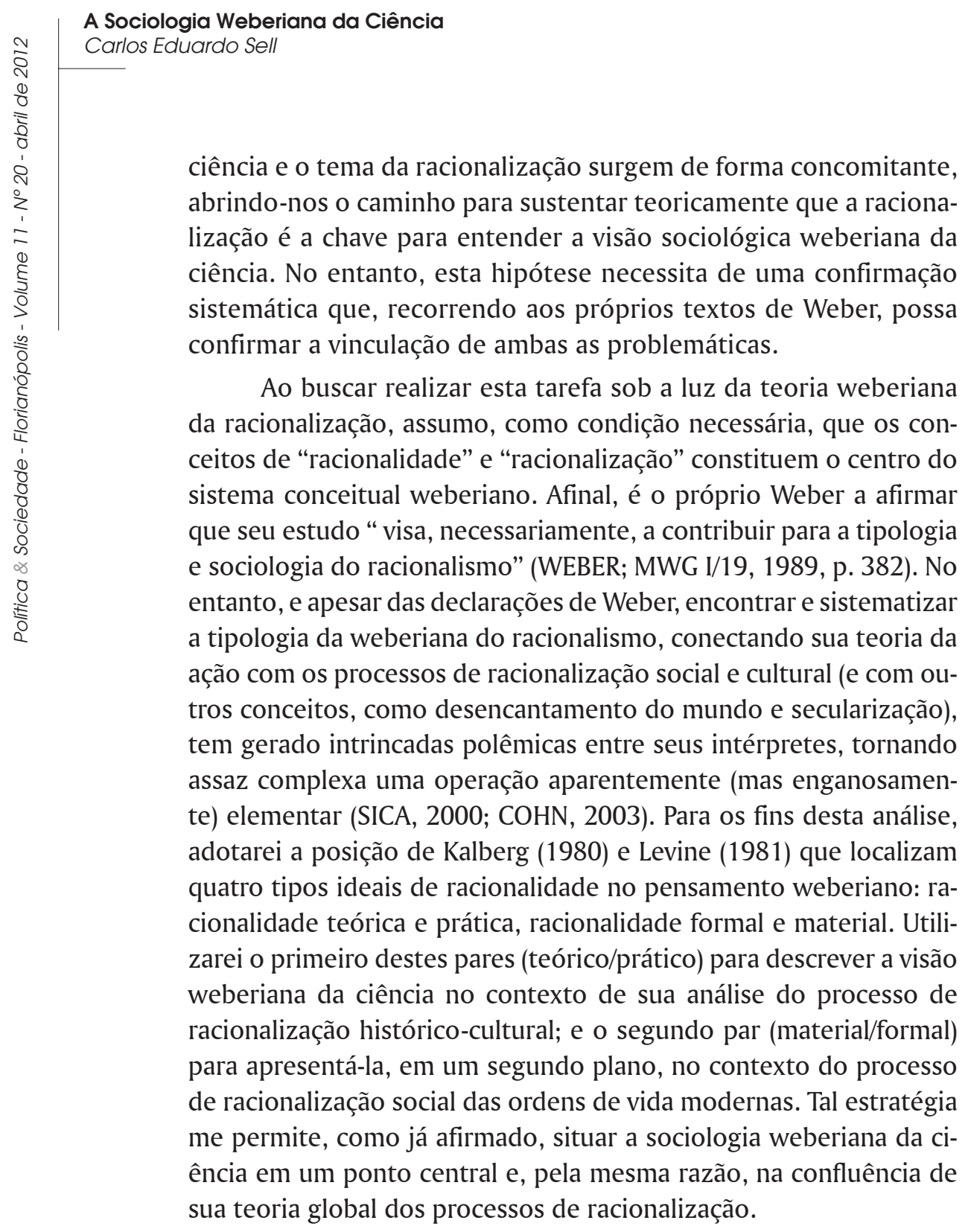

\section{Racionalidade teórica}

Como instrumental metodológico para entender a especificidade dos processos de racionalização das imagens do mundo 
no seio das grandes religiões universais, Weber nos apresenta dois critérios diferenciados. Ipsis verbis: "para apreciar o nível de racionalização que uma religião representa podemos usar dois critérios básicos (...). O primeiro é o grau em que uma religião despojou-se da magia; o outro é o grau de coerência sistemática que imprime à relação entre Deus e o mundo e, em consonância com isso, à sua própria relação ética com o mundo" (WEBER, 1991, p. 151). Mas, o que este esquema conceitual, cujo foco é a análise da racionalização religiosa, tem a ver com a ciência? Ora, se retomarmos o fio condutor deste duplo processo de racionalização, que é tanto teórico quanto prático (ou cognitivo e ético), veremos claramente que a ciência situa-se na primeira das linhas em questão: a racionalização científica representa a continuidade de um longo processo de racionalização teórica cujo fio condutor é o processo de desencantamento do mundo. Para explicitar esta tese vou recorrer a dois estudos que, de forma complementar, aprofundam ambos os elementos separadamente.

O primeiro destes trabalhos (SCHLUCHTER, 1979, p. 11-64) me permitirá demonstrar qual a conexão que liga a esfera científica com a esfera religiosa, ou seja, de que forma, a partir da sociologia weberiana da religião podemos descortinar, também, sua sociologia da ciência. Para tanto, adotarei o esquema neoevolucionista de Schluchter, procedimento mediante o qual este intérprete identifica na sociologia weberiana uma evolução de três diferentes visões de mundo (mágico-monista, teocêntrico-dualista e dualístico-imanente) que se desdobram segundo três momentos históricos subsequentes, marcados pelo predomínio da magia, da religião e da ciência. Examinemos este esquema com vagar ${ }^{7}$.

0 primeiro destes momentos nos remete à distinção weberiana entre "magia" e "religião". A religião, enquanto culto à divindade, já representa um estágio avançado de complexificação da visão de mundo, cujo ponto de partida é a magia (coação

7 Outra apresentação deste esquema pode ser encontrada, também, no texto de Souza (2000, p. 19-42). 
sobre o divino). $\mathrm{O}$ pressuposto que permeia a visão mágica do mundo é o naturalismo pré-animista, na qual se imagina que as forças difusas e imanentes que permeiam a realidade possam ser mobilizadas para os fins humanos mediante procedimentos adequados (mágicos). Segue, como segundo passo, o animismo, ou crença em almas, estágio que, por sua vez, já supõe a diferenciação entre objetos naturais e entidades sobrenaturais. Esta diferenciação abre caminho para o simbolismo, ou seja, para o processo de abstração dos poderes sobrenaturais e sua personificação na figura das divindades, configurando, então, a religião. O estágio mágico, em seus diferentes desenvolvimentos, possui como pano de fundo uma visão monista de mundo, dada pelo fato de que os poderes naturais ou sobrenaturais se sobrepõem e se identificam com a própria realidade.

O segundo momento nos remete à dinâmica interna da esfera religiosa que é descrita por Weber na Einleitung (Introdução ${ }^{8}$ ). A diferenciação entre o mundo natural e o mundo simbólico abre caminho para a constituição da esfera religiosa enquanto espaço autônomo e, neste caso, para a visão teocêntrico-dualista do mundo (sagrado x profano). Neste novo estágio sistêmico emerge o problema das relações entre a ordem moral da esfera religiosa e a esfera profana da ordem mundana. Este problema (que constitui o núcleo da teodiceia religiosa) recebe diferentes respostas culturais e é a partir delas que Weber diferencia as características das religiões ocidentais e orientais. Enquanto no caso das religiões da China esta tensão é atenuada mediante uma forma particular de racionalismo da acomodação ao mundo, no caso indiano e ocidental desenham-se duas fórmulas diferenciadas de rejeição do mundo: a fuga mística, por um lado (hinduísmo e budismo) ou a dominação ascética do mundo (protestantismo), por outro.

A ciência representa um terceiro passo ao longo deste processo de evolução e complexificação das imagens do mundo. No

8 Na tradução de Ghert e Mills este recebeu o título de "A psicologia social das religiões mundiais". 
entanto, Weber rejeita a tese de que a perspectiva científica deva ser considerada como uma visão monista da realidade. Aceitos estes termos, a ciência seria uma substituta da religião cabendo-lhe ocupar no lugar daquela a determinação do sentido cognitivo e moral da realidade. Na visão de Weber, na medida em que a religião especializou-se em determinar o sentido último da realidade em sua dimensão transcendente, restou aberto o caminho para que emergissem formas de compreensão intrínsecas do mundo, cujo propósito seria a elucidação dos mecanismos próprios de determinação teórica desta esfera. A visão científica seria imanente na medida em que não trata do mundo divino, mas do mundo natural e social, tomados em suas qualidades específicas. No entanto, ela continua dualista pois o saber científico não tem como substituir o papel filosófico e moral da religião cujo propósito é apontar o sentido ético e final da realidade. $\mathrm{O}$ dualismo fica preservado pois se conserva a diferenciação entre o ser (Sein) e o dever ser (Sollen), ou seja, entre fato e valor, barreira que, na visão weberiana, não poderia ser transposta. É exatamente este ponto que constitui, para Schluchter (1979), o paradoxo da racionalização ocidental, contradição que, na visão de Weber, colocou particulares desafios éticos para o homem moderno (tema que retomarei no final do trabalho).

Construído no marco da teoria weberiana da racionalização teórica, o estudo de Schluchter, a meu ver, acaba dando pouco destaque àquele que é o aspecto central desse processo histórico-cultural: o desencantamento do mundo 9 . Vou suprir esta lacuna lançando mão de outro trabalho sistemático, desta feita, de Antonio Flávio Pierucci (2003). Após um cuidadoso trabalho de rastreamento do termo "Entzauberung der Welt" nos escritos weberianos, Pierucci sustenta que as 17 passagens existentes apontam para um sentido duplo e concomitante que lhe dá forma. Estes dois sentidos seriam: a) o desencantamento do mundo pela religião e, b) o desencantamento do mundo pela ciência. No trabalho de Pierucci, portanto, repete-se a mesma estrutura da abordagem de Schluchter, figurando a ciência

9 Mais recentemente, o autor trata do assunto em: Schluchter (2009, p. 01-14). 


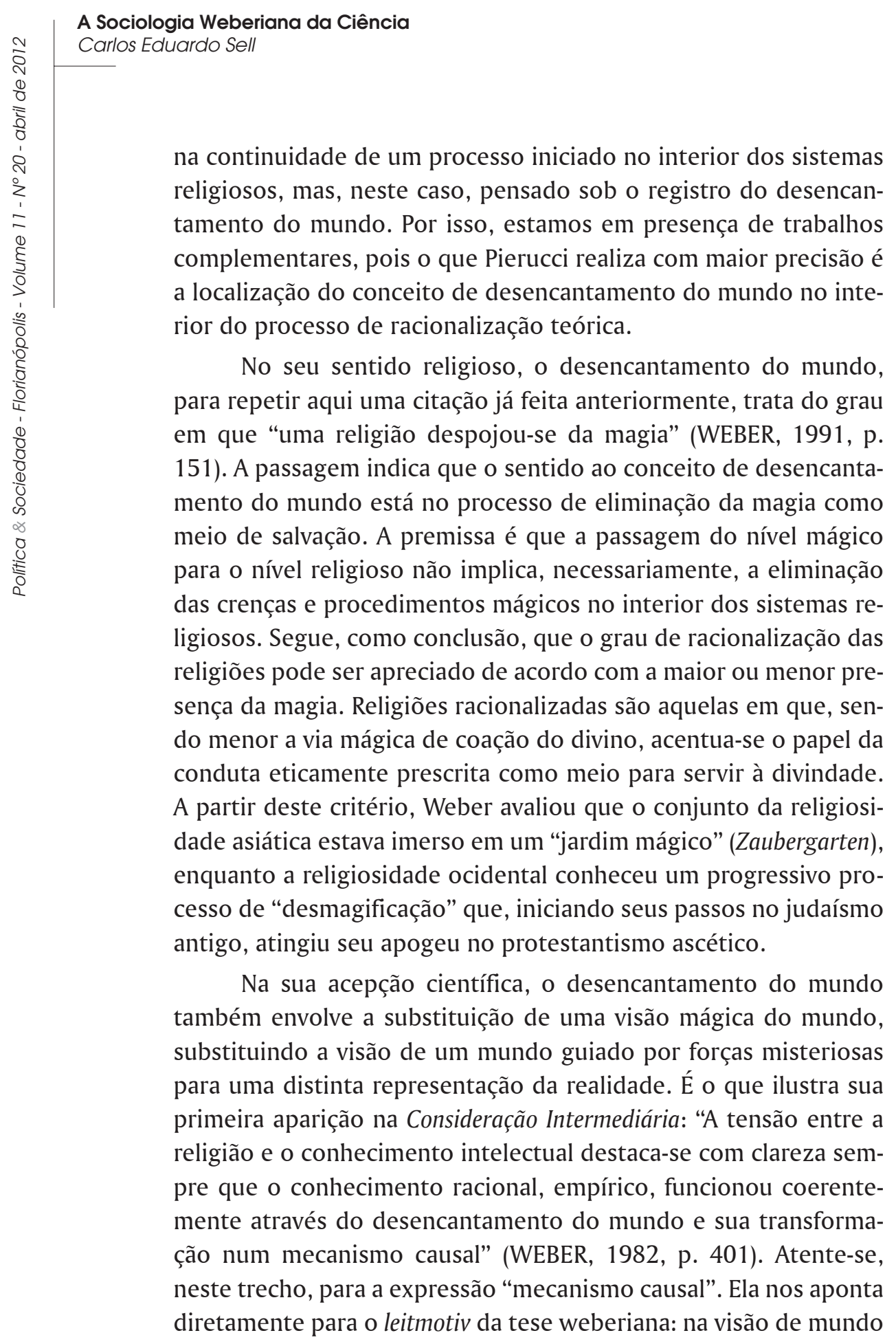


proposta pela ciência, forças mágicas ou mesmo o sentido último da realidade (metafísica) são substituídos por uma interpretação que se limita a descrever a dinâmica causal e contingente que rege a relação entre os fenômenos. Mesma tese que vamos encontrar em $A$ ciência como vocação, escrito no qual Weber vincula o vocábulo desencantamento do mundo aos termos interligados de racionalização e intelectualização:

A intelectualização e a racionalização crescentes não equivalem, portanto, a um conhecimento geral crescente acerca das condições em que vivemos. Significam, antes, que sabemos ou acreditamos que, a qualquer instante, poderíamos, bastando que o quiséssemos, provar que não existe, em princípio, nenhum poder misterioso e imprevisível que interfira com o curso de nossa vida; em uma palavra, que podemos dominar tudo, por meio da previsão. Equivale isso a despojar de magia o mundo. Para nós não mais se trata, como para o selvagem que acredita na existência daqueles poderes, de apelar a meios mágicos para dominar os espíritos ou exorcizá-los, mas de recorrer à técnica e à previsão. Tal é a significação essencial da intelectualização (WEBER, 1967, p. 30-31).

Nesta mesma passagem há uma interessante associação causal entre magia e ciência, ao qual gostaria de dar destaque. Segundo argumentação de Weber, se a religião se racionaliza na medida em que expugna os traços mágicos de seu interior, a ciência substitui os meios mágicos pelo "domínio calculador" do mundo. Este tópico nos traz imediatamente à lembrança uma tese que será explorada mais tarde por Adorno e Horkheimer e que, certamente não por acaso, dirão que "o programa do esclarecimento era o desencantamento do mundo" (ADORNO; HORKHEIMER, 1985, p. 19). Diante desta constatação, surge, então, da pena de Weber, a seguinte pergunta: "Ora, esse processo de desencantamento (...) tem significação que ultrapasse essa pura prática e essa pura técnica?” (idem, p. 31).

Embora Weber tivesse sustentado que a atividade científica possa dar sentido à vida de um indivíduo, no que tange à vida cultural em seu sentido amplo, sabemos que a resposta de Weber era francamente negativa. A ciência, ao ler o mundo sob o registro da fria lógica causal da necessidade e do acaso, esvazia a realidade de 


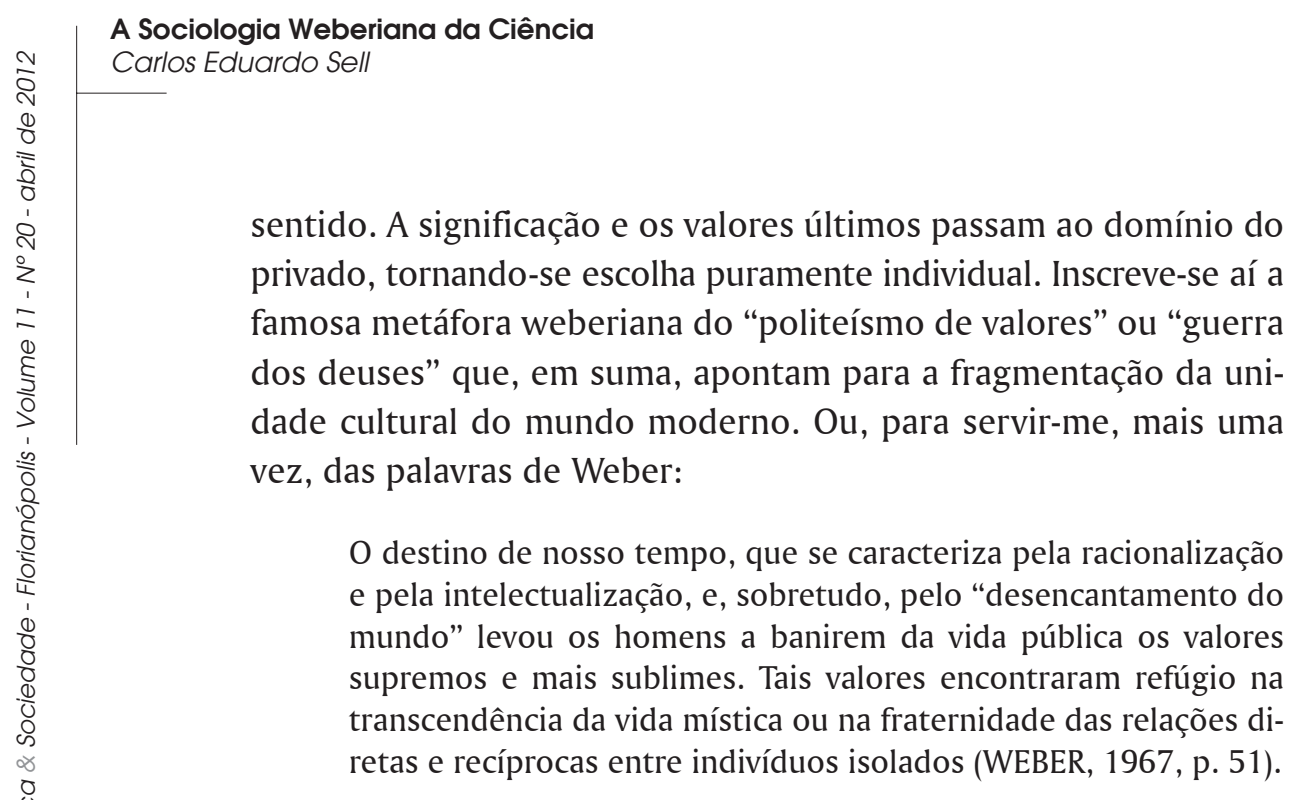

\section{Racionalidade formal}

Vimos, no tópico acima, que a dicotomia típico-ideal racionalidade teórica e prática possui seu sentido analítico no contexto da sociologia da religião de Weber, ou seja, serve-lhe como instrumento para compreender os processos de racionalização cultural das imagens do mundo. Sob tal ótica, a ciência, ao desencantar o mundo, representa o estágio moderno deste amplo processo de racionalização teórica que perpassou a história ocidental. Já o par típico-ideal racionalidade material e formal aparece em outro contexto, a saber, nos escritos que compõem Economia e Sociedade. Por isso, podemos supor que sua função analítica é diferente e acompanha o objetivo deste mesmo texto, qual seja, apresentar uma sociologia teórico-sistemática que descreva a compreensão da dinâmica das instituições racionalizadas da modernidade (economia, direito, dominação política, classes sociais, grupos étnicos etc). Dito de outra forma, ela serve a Weber como instrumento para compreender os processos de racionalização social das ordens de vida modernas. Que implicações esta abordagem possui para a sociologia weberiana da ciência?

Anteriormente, já tínhamos chamado a atenção do leitor para o fato de que, ao contrário de temas como economia, direito 
e política, não encontramos em Economia e Sociedade um capítulo ou seção específica em que Weber nos brinda com uma análise própria da esfera científica. Estaríamos, então, impedidos de encontrar em seu pensamento uma sociologia particularizada da ciência? ${ }^{10}$ Meu propósito será mostrar que não; mas, para tanto, teremos que, inevitavelmente, prosseguir nossa reconstrução da argumentação weberiana a esse respeito pela via indireta ${ }^{11}$.

Começo com as contribuições que podemos extrair de $A$ ciência como vocação, entre elas, as preciosas indicações pelas quais Weber nos informa sobre como ele enxergava a origem histórica da ciência. Ainda que esquemática, dada à finalidade daquele escrito, ficamos sabendo que na visão weberiana o surgimento da ciência vem associado a dois passos diferentes, construídos em distintos períodos históricos. O primeiro destes períodos nos remete ao mundo antigo e à civilização grega, tendo em vista que, naquela época "haver sido descoberto o sentido de um dos maiores instrumentos do conhecimento científico: o conceito" (WEBER, 1967, p. 32-33). Weber tinha consciência de que "em nenhum outro lugar que não a Grécia percebe-se a consciência da importância do conceito", pois, "foram os gregos os primeiros a saberem utilizar esse instrumento que permitia prender qualquer pessoa aos grilhões da lógica" (idem, p. 33). O segundo passo, por sua vez, nos coloca no alvorecer da era moderna: "a essa descoberta do espírito helênico associou-se, depois, o segundo grande instrumento do trabalho científico, engendrado pelo Renascimento: a experimentação racional" (idem, p. 33). Sem este elemento, assevera Weber, "a ciência empírica moderna não teria sido possível" (idem, p. 33). Não escapou ao olhar atento do pensador o fato de que ex-

10 Talvez esta dificuldade tenha impedido que até mesmo a excelente e respeitada sistematização de Freund (1987) localizasse em Weber uma sociologia especial da esfera da economia, da religião, da política, do direito e até mesmo da arte e da técnica, mas, infelizmente, nada se diz sobre sua sociologia da ciência.

11 Sugestão que também pude encontrar em Kalberg (2002, p. 190). Este autor aponta para a ideia de reconstruir os elementos da visão weberiana da ciência a partir do capítulo de sociologia da religião de Economia e Sociedade que trata do papel dos intelectuais na esfera religiosa. 


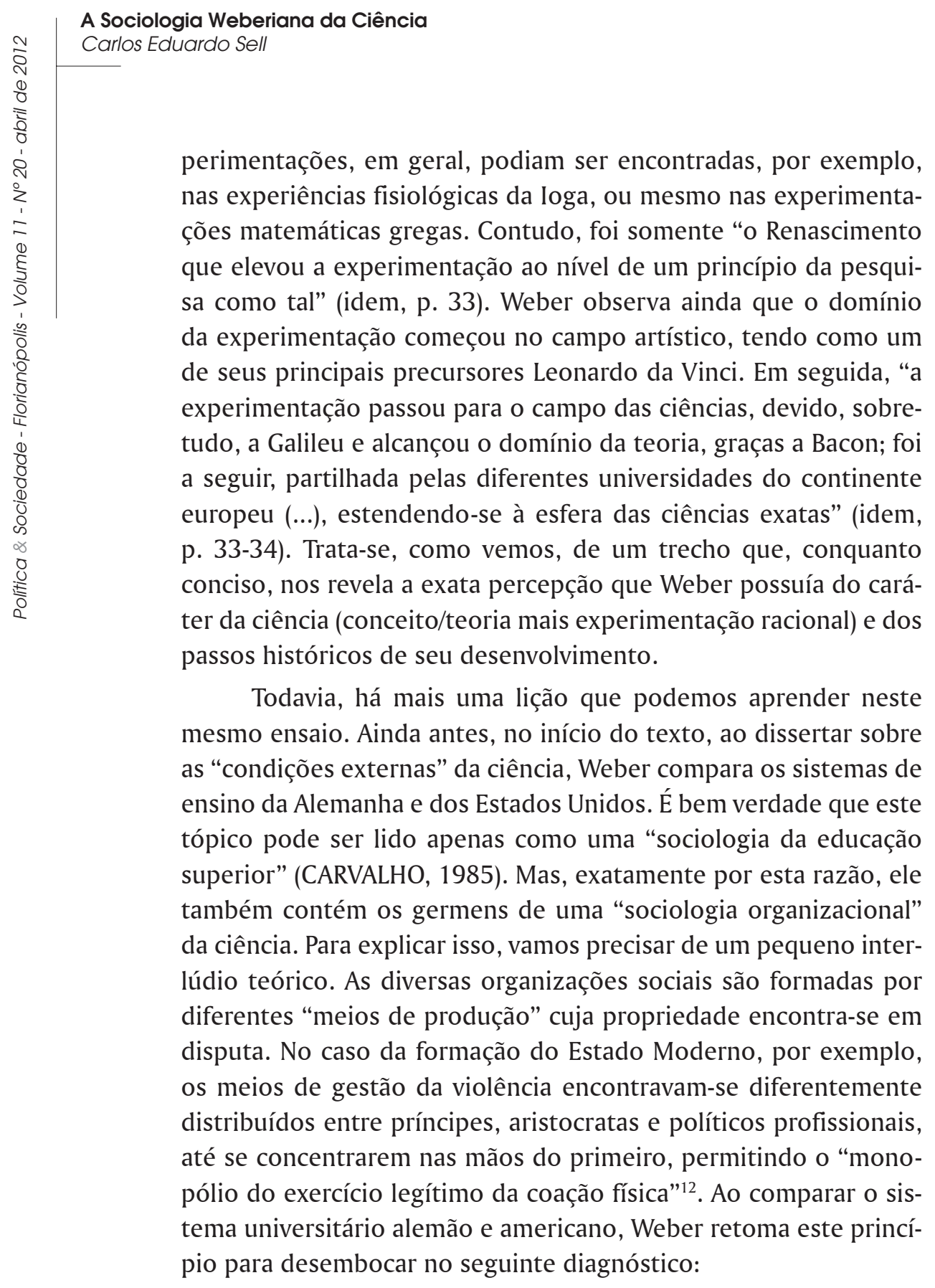

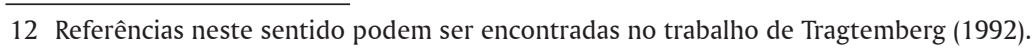


Nos últimos tempos, podemos observar claramente que, em numerosos domínios da ciência, desenvolvimentos recentes do sistema universitário alemão orientam-se de acordo com padrões do sistema norte-americano. Os grandes institutos de ciência e de medicina transformaram-se em empresas de 'capitalismo estatal'. Já não é possível geri-las sem dispor de recursos financeiros consideráveis. E nota-se o surgimento, como aliás em todos os lugares em que se implanta uma empresa capitalista, do fenômeno específico do capitalismo, que é o de 'privar o trabalhador dos meios de produção’ (WEBER, 1967, p. 19).

Na linguagem de Weber, a universidade alemã estava transitando do modelo plutocrático (no qual o cientista é proprietário dos meios de produção) para o burocrático (no qual os meios de produção intelectual pertencem ao Estado). Para ele, "tal como se dá com outros setores de nossa vida, a universidade alemã se americaniza, sob importantes aspectos", além de que "a evolução se processa, contudo, a grandes passos” (idem, p. 20).

Ainda que claramente sociológicos, tais elementos históricos e estruturais não representam material suficiente para, por si só, comporem uma "sociologia da ciência”, de caráter específico e sistemático. Isoladamente, elas até mostram acuradas percepções empírico-sociológicas, mas não nos permitem dar o passo decisivo: analisar a ciência como esfera social autônoma. Se o texto de A ciência como vocação não nos fornece bases suficientes para tanto, talvez este não seja o caso daquele outro texto do qual vimos fazendo menos referência até agora: a Consideração Intermediária.

O fato de estar situado no contexto da sociologia weberiana da religião pode levar o leitor a considerar que a Consideração Intermediária é apenas mais um dos textos especializados apenas neste assunto. Muito ao contrário, o escrito em questão possui um escopo muito mais amplo do que aparenta: nele encontramos uma autêntica teoria sociológica da modernidade. Para explicar este importante ponto recorro, novamente, à exposição de Habermas, que nos esclarece que "o tema da Zwischenbetrachtung são esses conflitos de raiz interna que, segundo Weber, têm forçosamente que produzir-se entre a ética da fraternidade quanto esta é objeto de 


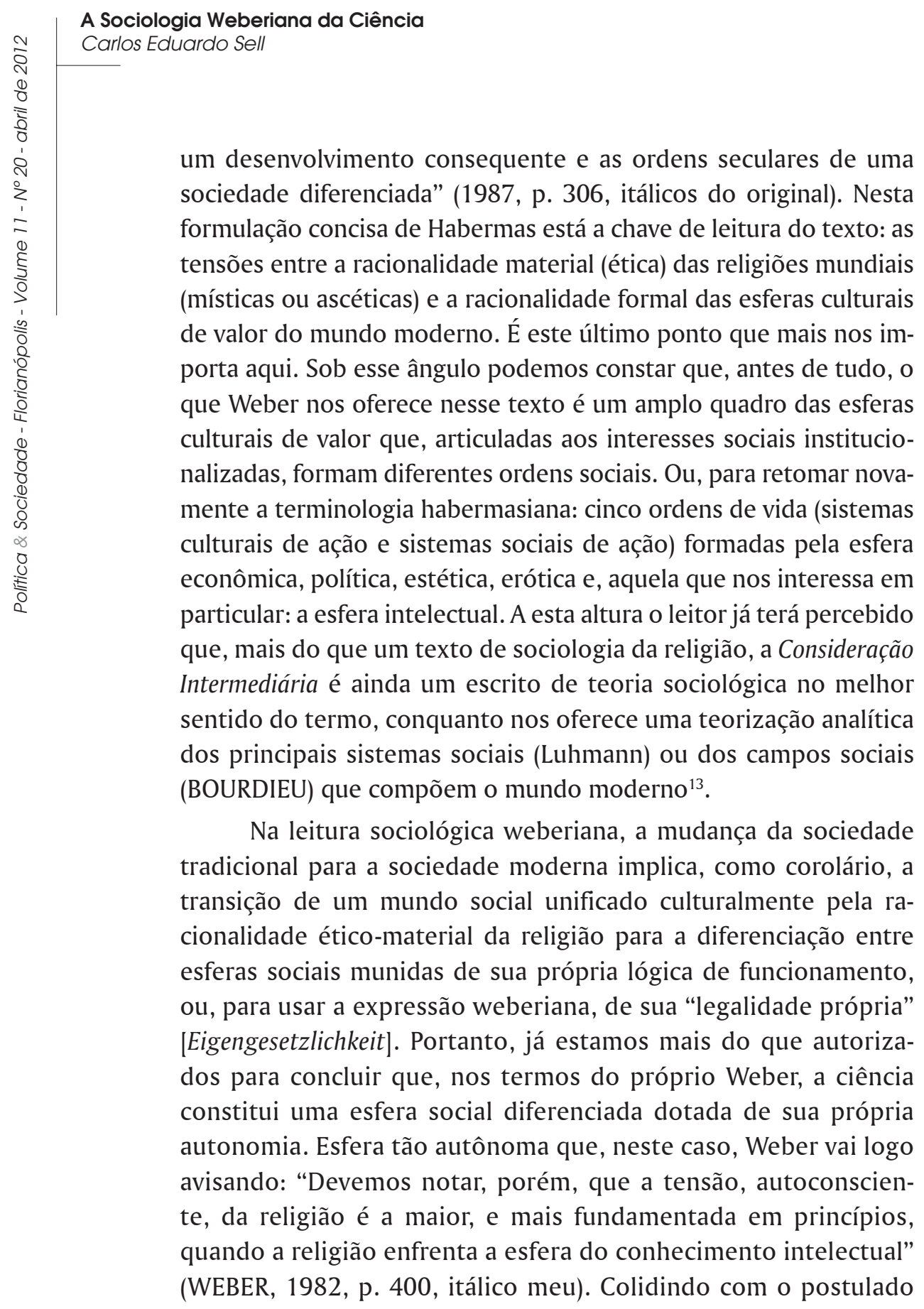

13 Autoriza-me a aproximar estes diferentes conceitos o preciso trabalho de Bruun (2008). 
ético de que o mundo é um cosmo ordenado por Deus, a visão de mundo implícita na ciência "apresenta refutações a qualquer abordagem intelectual que, de alguma forma, exija um 'significado' para as ocorrências do mundo interior” (idem, p. 401). Neste embate de interesses, o resultado para o sistema religioso é que "todo aumento do racionalismo na ciência empírica leva a religião, cada vez mais, do reino racional para o irracional" (idem, p. 401). Isto significa que, ao institucionalizar-se, a esfera social autônoma da ciência monopoliza a produção do saber considerado racional.

De um lado, o cosmo da causalidade ética da religião e, do outro, o cosmo da causalidade natural da ciência. É neste segundo aspecto que repousa a racionalidade formal da esfera científica. Para retomar os termos de Habermas, a ciência, como esfera cultural de valor, representa a dimensão expressiva da cultura e, como espaço organizado do saber, encarna uma forma específica de legalidade: a racionalidade cognitivo-instrumental. É nesta dimensão que reside sua especificidade enquanto "sistema" ou "campo" e é ela que constitui a sua legalidade própria. Neste espaço, os atores regem-se por princípios inerentes que, ainda que de forma alusiva, também foram identificados por Max Weber: "o intelecto, como todos os valores culturais, criou uma aristocracia baseada na posse da cultura racional" (idem, p. 406). Os atores que compõem este campo formam, então, uma "aristocracia não fraternal do saber” cujo objetivo é a busca deste saber enquanto valor intrínseco. Mas, relacionar a ciência com os valores já é outro problema. Vamos tratar deste tema em nossa seção final.

\section{Considerações finais: a ciência e a ética}

Dado o objetivo deste trabalho, este texto bem poderia terminar por aqui, restando-nos apenas uma síntese conclusiva. Com base no levantamento realizado penso que é possível sustentar que a (proto) sociologia da ciência de Weber possui uma dupla dimensão. Na primeira, de caráter amplo e histórico-cultural, a 


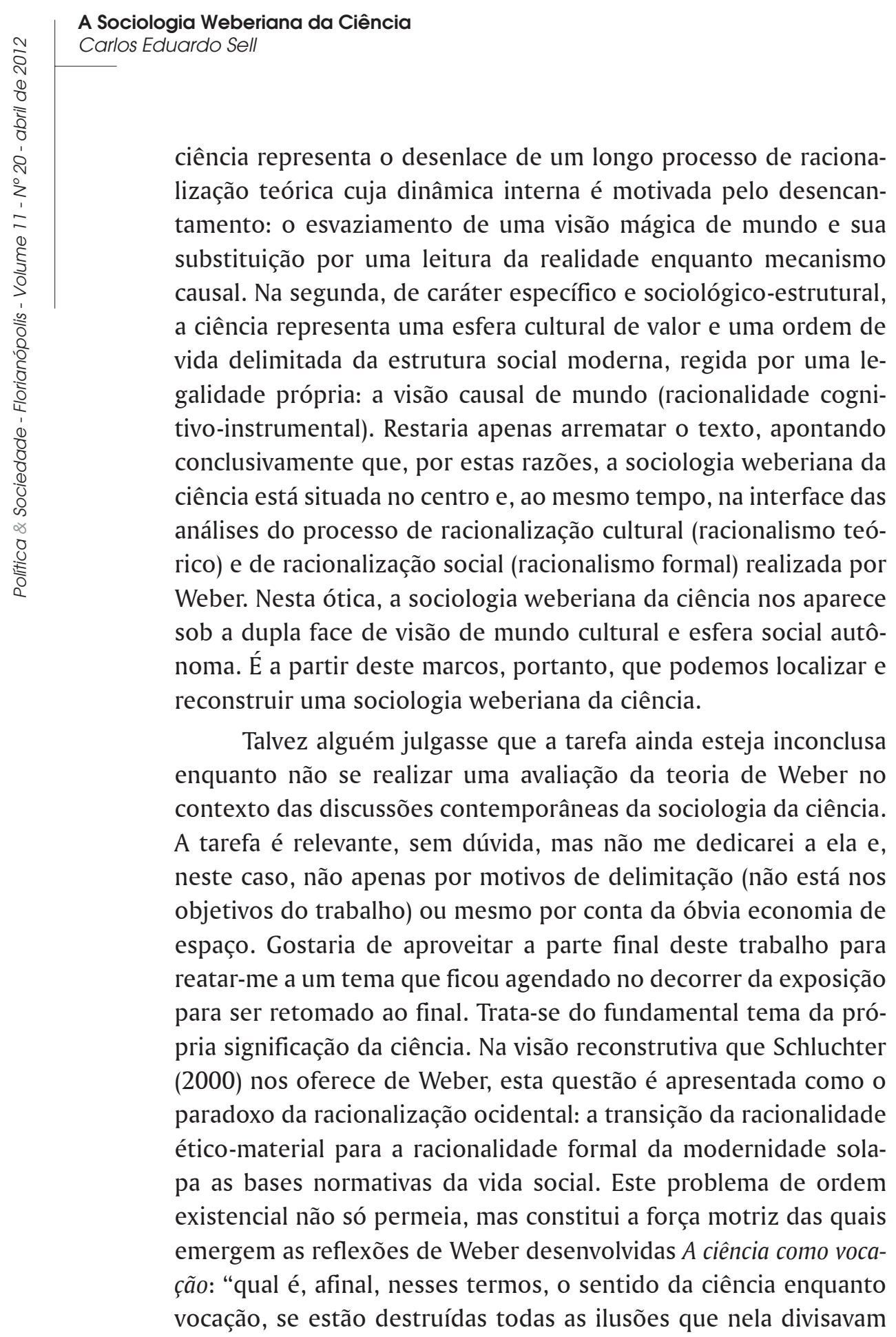


o caminho que conduz ao 'ser verdadeiro', à 'verdadeira arte', à 'verdadeira natureza', ao 'verdadeiro Deus', à 'verdadeira felicidade'?” (1967, p. 35). Este mesmo paradoxo ganha cores ainda mais vivas se lembrarmos das análises políticas de Weber, esfera na qual o peso da burocratização o levou a concluir pelo advento de uma "concha da servidão". Mesma tonalidade podemos encontrar ainda em sua análise dos processos econômicos, tendo em vista que a autonomização da lógica da acumulação para além de suas bases puritanas (a ética do trabalho qual leve manto) nos encaminhava para uma "rija crosta de aço". Na parte final da A ética protestante e o 'espírito' do capitalismo, por sinal, o destino que era reservado para o ser humano diante de uma vida social que se congelava ao sabor de sua ordem imanente foi expresso por Weber de forma não menos dramática: "Então, para os 'últimos homens' desse desenvolvimento cultural, bem poderiam tornar-se verdade as palavras 'especialistas sem espírito, gozadores sem coração: esse Nada imagina ter chegado a um grau de humanidade nunca antes alcançado" (WEBER, 2004, p. 166). O que esta reflexão nos traz à tona é que a sociologia weberiana da ciência não é apenas global e específica, cultural e social, teórica e formal, histórica é sistemática: ela é também crítica e existencial. Esta preocupação constitui a fonte e o berço das preocupações de Weber e, por essa razão, este horizonte informa e incorpora sua visão da ciência e, neste sentido, podemos dizer que ela se sobrepõe às demais. Desligar a sociologia weberiana da ciência desta dimensão crítico-normativa é amputar-lhe toda e qualquer possibilidade de compreensão.

Este olhar crítico, por sua vez, também possui uma dupla face, na medida e em que se expressa enquanto "diagnóstico" e "prognóstico", ou seja, parte da identificação das contradições da realidade para, a partir dela, apontar as possibilidades de sua superação ${ }^{14}$. Nesta direção, diferente do que possa sugerir a usual caracterização de Weber como intelectual "pessimista" ou "desesperado", de tons

14 Em Schluchter esta dupla dimensão (descritivo/prescritiva) é tematizada como "sistemas de valor institucionalizados" e "categoria metodológica e ética" (SCHLUCHTER, 2000). 


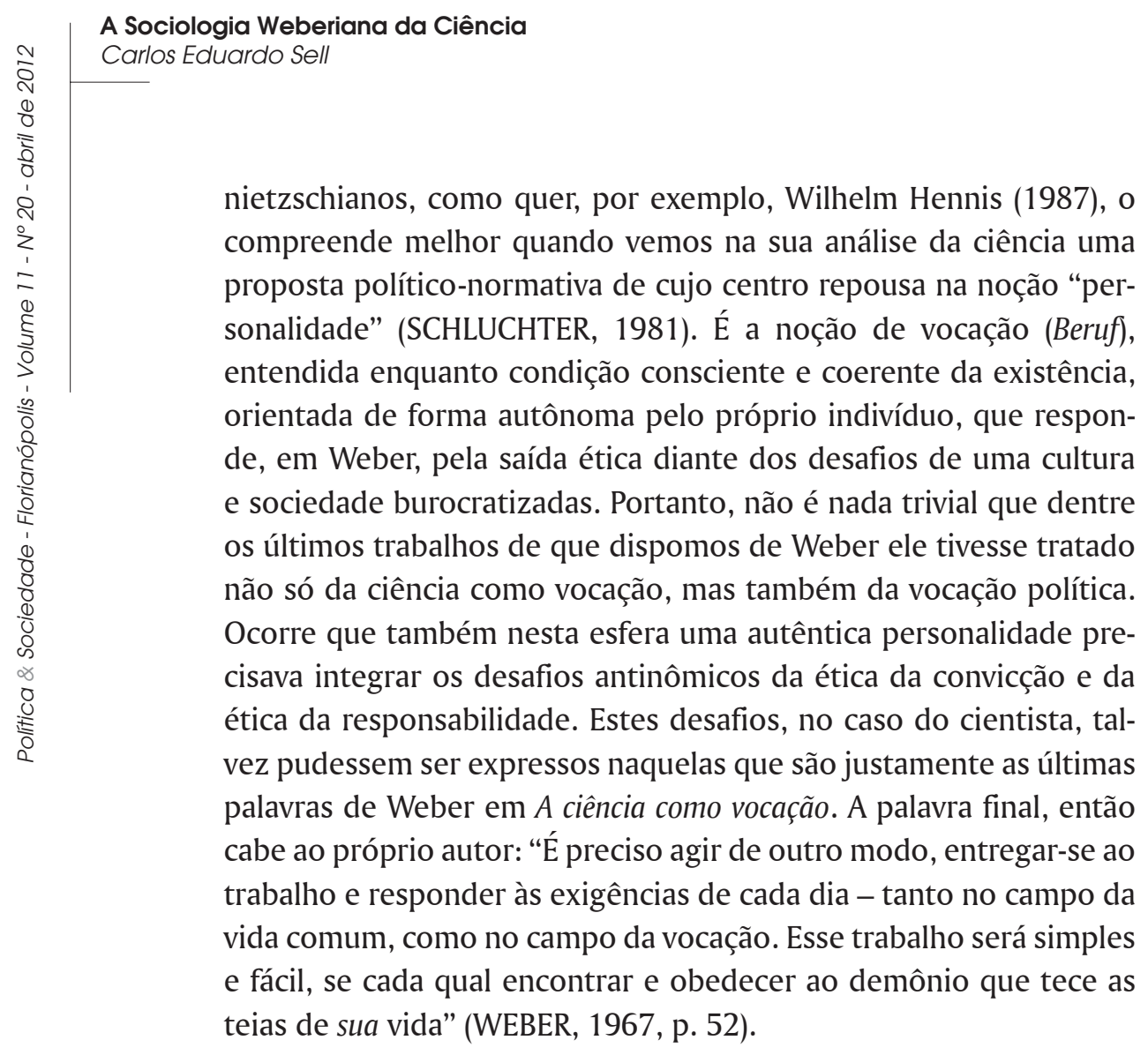

Original recebido em: 08/11/2011 Versão final recebida em: 16/03/2012

\section{Referências}

ADORNO, Theodor; HORKHEIMER, Max. Dialética do esclarecimento. Rio de Janeiro: Jorge Zahar, 1985.

BRUUN, Hans Henrik. Objectivity, Value Spheres and 'Inherent Laws': On some Suggestive Isomorphisms between Weber, Bourdieu and Luhmann. Philosophy of the Social Sciences, v. 38, p. 97-120, 2008.

CARVALHO, Aloísio Bezerra de. Max Weber: modernidade, ciência e educação. Petrópolis: Vozes, 2005. 
COHEN, Bernard (Ed.). Puritanism and The Rise of Science. New Brunswick: Rutgers University Press, 1990.

COHN, Gabriel. Crítica e resignação. São Paulo: Martins Fontes, 2003.

FERNANDES, Ana Maria. A ciência, o cientista e a política. In: Política, ciência e cultura em Max Weber. Maria Francisca Pinheiro Coelho; et al. (Orgs.). Brasília: UnB, 2000. p. 197-204.

FREUND, Julien. Sociologia de Max Weber. Rio de Janeiro: Forense Universitária, 1987. 4. ed.

HABERMAS, Jürgen. Teoria da la acción comunicativa: racionalidad de la acción y racionalización social. Madrid: Taurus, 1987.

HENNIS, Wilhelm. Max Webers Fragestellung. Studien zur Biographie des Werkes. Tübingen: Mohr Siebeck, 1987.

KALBERG, Stephen. Max Weber's types of rationality: Cornerstones for the Analisys of Rationalization Process in History. The American Journal of Sociology, v. 85, n. 05, p. 1145-1179, 1980.

KALBERG, Stephen. La sociologie historique comparative de Max Weber. Paris: La Decouverte, 2002.

KRAMER, Paulo. Alexis de Tocqueville e Max Weber: respostas políticas ao individualismo e ao desencantamento na sociedade moderna. In: SOUZA, Jessé (Org.). A atualidade de Max Weber. Brasília: Unb, 2000. p. 163-196.

LASSMANN, Peter e VELODY, Irving (Eds.). Max Weber 'Science as a Vocation'. London: Unwin, 1989.

LEVINE, Donald. Rationality and freedom: Weber and Beyond. Sociological Inquiry, v. 51, n. 1, p.05-25, 1981.

LÖWITH, Karl. Max Weber e Karl Marx. In: GERTZ, René E. Max Weber \& Karl Marx. São Paulo: Hucitec, 1997. 2. ed. p.17-31.

MALEY, Terry. Max Weber and the Iron Cage of Technology. Bulletin of Science, Technology \& Society, v. 24, p. 69-86, 2004.

MATTEDI, Marcos. Sociologia e conhecimento. Chapecó: Argos, 2006.

MENEZES, Marilde Loiola. Convicção e responsabilidade no campo científico. In: Política, ciência e cultura em Max Weber. 
Maria Francisca Pinheiro Coelho et al. (Orgs.). Brasília: UnB, 2000. p. 235-242.

MERTON, Robert K. Science, Technology and Society in Seventeenth-Century England. New York: Harper \& Row, 1970.

NOBRE, Renarde Freire. Perspectivas da razão: Nietzsche, Weber e o conhecimento. Belo Horizonte: Argumentum, 2004.

OKAES, Guy. The Antinomy of Values: Weber, Tolstoy and the Limits of Scientific Rationality. Journal of classical sociology, v. 1, p. 195-211, 2001.

PIERUCCI, Antônio Flávio. 0 desencantamento do mundo: todos os passos do conceito em Max Weber. São Paulo: Editora 34, 2003.

RINGER, Fritz. A metodologia de Max Weber. São Paulo: Edusp, 2004.

SAINT-PIERRE, Héctor. Max Weber entre a paixão e razão. Campinas: Unicamp, 1994. 2. ed.

SCHLUCHTER, Wolfgang. Max Weber vision of history. Berkeley: Califórnia Press, 1979.

SCHLUCHTER, Wolfgang. The rise of Western rationalism: Max Weber's development history. Berkeley: Califórnia Press, 1981.

SCHLUCHTER, Wolfgang. Neutralidade de valor e ética da responsabilidade. Política, ciência e cultura em Max Weber. Maria Francisca Pinheiro Coelho et al. (Orgs.). Brasília: UnB, 2000. p. 55-110.

SCHLUCHTER, Wolfgang. 'Die Entzauberung der Welt': Max Webers Sicht auf die Moderne. In Die Entzauberung der Welt. Tübingen: Mohr Siebeck, 2009, p. 01-17.

SCHROEDER, Ralph e SWEDBERG, Richard. Weberian Perspectives on Science, Technology and the Economy. British Journal of Sociology, v. 53, p. 383- 401, 2002.

SCHROEDER, Ralph. Disenchantment and Its Discontents: Weberian Perspectives on Science and Technology. Sociological Review, v. 43, p. 227-250, 1995. 
SELL, Carlos Eduardo. Imagens de Weber: esboço de uma tipologia das interpretações do pensamento weberiano. In: XIV Congresso Brasileiro de Sociologia, Paper, Rio de Janeiro, 2009.

SICA, Alan. Rationalization and culture. In: TURNER, Stephen (eds.). The Cambridge Companion to Weber. Cambridge: University Press, 2000, p. 42-58.

SOUZA, Jessé. Patologias da modernidade: um diálogo entre Habermas e Weber. Rio de Janeiro: Anablume, 1997.

SOUZA, Jessé. Max Weber e a singularidade da cultura ocidental. A modernização seletiva: uma renterpretação do dilema brasileiro. Brasília: UnB, 2000. p. 19-35.

TENBRUCK, Friedrich. Max Weber and the Sociology of Science: A Case Reoponed. Zeitschrift fuir Soziologie, v. 3, p. 312-321, 1974.

TENBRUCK, Friedrich. The problem of thematic unity in the Works of Max Weber. British Journal of sociology, v. 30, p. 199-113, 1980.

TRAGTEMBERG, Maurício. Burocracia e ideologia. São Paulo: Ática, 1992. 2. ed.

TRIGUEIRO, Michelangelo Giotto Santoro. O cientista e o político nas biotecnologias. Política, ciência e cultura em Max Weber. In: Maria Francisca Pinheiro Coelho et al. (Orgs.). Brasília: UnB, 2000. p. 205-234.

WAIZBORT, Leopoldo. Introdução. In: WEBER, Max. Os fundamentos racionais e sociológicos da música. São Paulo: Edusp, 1995. p. 23-52.

WEBER, Max. Ciência e política: duas vocações. São Paulo: Cultrix, 1967.

WEBER, Max. A psicologia social das religiões mundiais (Einleintug). In:___ . Ensaios de sociologia. Rio de Janeiro: Guanabara, 1982. 5. ed. p. 309-346.

WEBER, Max. Rejeições religiosas do mundo e suas direções (Zwischenbetrachtung). In: . Ensaios de sociologia. Rio de Janeiro: Guanabara, 1982. 5. ed. p. 371-410. 


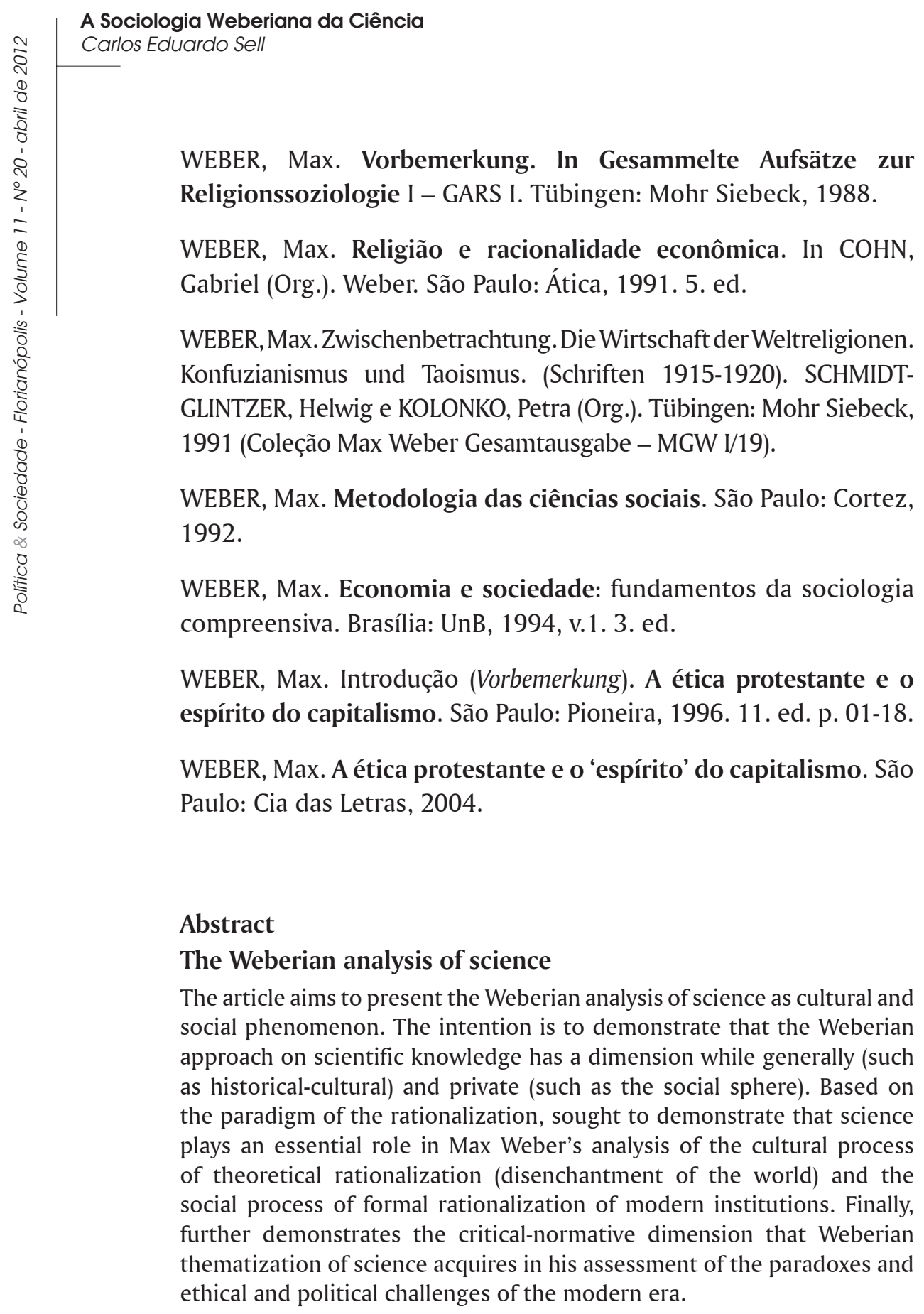

Keywords: science, rationality, rationalism. 